\title{
Evaluation and Clustering Analysis on the Development of Urban Agglomerations in the Yangtze River Economic Belt
}

\author{
Chun $\mathrm{CHEN}^{* 1 a}$, Xiang $\mathrm{GAO}^{2, \mathrm{~b}}$ \\ ${ }^{1}$ Professor,Business School, Sichuan Normal University, Chengdu 610101, China \\ ${ }^{2}$ postgraduate student,Information School, the University of Sheffield, \\ Sheffield S10 2TN, the United Kingdom \\ achenchun@sina.com, ${ }^{\mathrm{b}} 2846857801 @ q q . c o m$
}

Keywords:The Yangtze River Economic Belt, Chengdu Chongqing economic zone, The Yangtze River delta economic zone, Wuhan economic circle.

\begin{abstract}
Based on the urbanization development index system, the paper constructs a factor analysis and hierarchical clustering analysis model of urban economic development in the Yangtze River Economic Belt, and conducts comprehensive evaluation on the economic development of 71 cities from Shanghai, Jiangsu, Zhejiang, and Hubei province. The cities have comprehensive strength for development are Shanghai, Chongqing, Hangzhou, Suzhou, Chengdu, etc. It's better to put forward further in-depth analysis of specific conditions of these urban economic development, and strategic suggestions. Hoping that this can better promote the economic development of the Yangtze River Economic Belt urban agglomeration.
\end{abstract}

\section{Introduction}

The Yangtze River Economic Belt is an economic development corridor spanning three major areas in eastern, central and western China. To facilitate the transportation or radiation of industries' potential development, there exitsYangtze River Delta Economic Zone, Wanjiang Economic Zone, Wuhan Economic Zone and Chengdu-Chongqing Economic Zone, which play decisive roles in promoting interaction and coordinated development of eastern, central and western regions. The Yangtze River Delta Economic Zone is China's strongest comprehensive region[1], including Shanghai, Jiangsu and Zhejiang. The Pan-Yangtze River Delta Economic Zone includes the Wanjiang Economic Belt. The Wanjiang Economic Belt refers to the Anhui Economic Zone and serves as a link to expansion and development of the Yangtze River Delta economic zone [2]. Wuhan Economic Circle refers to the largest and most dense urban agglomeration centered on Wuhan. It reaches an important economic growth pole in inland areas of China[3]. Chengdu-Chongqing Economic Zone, with Chongqing and Chengdu as the center, includes the economic zone of Sichuan. In the strategic pattern of China productive forces space [4], it is important in helping the East go to the west.The research on the economic development of the Yangtze River Delta has been a hot spot for domestic scholars. However, there are relatively few economic studies over Wuhan Economic Zone and Chengdu-Chongqing Economic Zone and the Yangtze River Economic Zone. This paper establishes a factor analysis and level analysis model of urban economic development in the Yangtze River Economic Belt. By using 15 indicators, this paper analyzes development strategies of 71 cities in Shanghai, Jiangsu, Zhejiang, Hubei, Sichuan and Chongqing. Hopeto promote the development of urban agglomerations in the Yangtze River economic belt.

\section{Construct Index System and Data Preparation}

\section{Construct Index System}

In this paper, factor analysis and analytic hierarchy process (AHP) are used to evaluate. Based on the specific conditions of 71 cities in Shanghai, Jiangsu, Zhejiang, Hubei, this paper considers 
economic, technological, population and education aspects. 29 items are selected as indicators of the urban economic development in the Yangtze River economic belt, as shown in Table 1.

Table 1.Evaluation Index System for the Development of 71 Cities along theYangtze River Economic Belt

\begin{tabular}{|l|l|l|l|l|l|}
\hline X01 & Urban population & X11 & Total retail sales & X21 & Number of doctors \\
\hline X02 & Population growth rate & X12 & Resident savings balance & X22 & Per capita road area \\
\hline X03 & $\begin{array}{l}\text { Administrative area of land } \\
\text { area }\end{array}$ & X13 & $\begin{array}{l}\text { The actual amount of } \\
\text { foreign investment }\end{array}$ & X23 & Total passenger volume \\
\hline X04 & $\begin{array}{l}\text { Gross domestic product } \\
\text { GDP }\end{array}$ & X14 & Technology spending & X24 & Total freight \\
\hline X05 & Investment in fixed assets & X15 & Education spending & X25 & $\begin{array}{l}\text { The number of buses per } \\
10,000 \text { people }\end{array}$ \\
\hline X06 & Local budget revenue & X16 & $\begin{array}{l}\text { Number of colleges and } \\
\text { universities }\end{array}$ & X26 & Per capita green area \\
\hline X07 & $\begin{array}{l}\text { The proportion of secondary } \\
\text { industry GDP }\end{array}$ & X17 & $\begin{array}{l}\text { Hundreds of people } \\
\text { library collection }\end{array}$ & X27 & $\begin{array}{l}\text { Built-up area green } \\
\text { coverage }\end{array}$ \\
\hline X08 & $\begin{array}{l}\text { The proportion of tertiary } \\
\text { industry GDP }\end{array}$ & X18 & $\begin{array}{l}\text { Number of local phone } \\
\text { users }\end{array}$ & X28 & $\begin{array}{l}\text { Environmental } \\
\text { governance investment }\end{array}$ \\
\hline X09 & Number of employees & X19 & Mobile phone users & X29 & The total profit \\
\hline X10 & Total employee wages & X20 & Internet users & & \\
\hline
\end{tabular}

\section{Data Preparation}

This paper uses "China City Statistical Yearbook 2017"[5], and "Jiangsu Statistical Yearbook 2017” [6], "Sichuan Statistical Yearbook 2017” [7], "Hubei Statistical Yearbook 2017" [8] and so on.

\section{Data Analysis}

Unweighted least squares factor analysis and hierarchical cluster analysis are used to implement the Yangtze River economic belt urban data analysis. The tool is the SPSS statistical software.

\section{Unweighted Least Squares Factor Analysis}

Table 2.Common Factors of Variables

\begin{tabular}{|c|r|r|c|r|r|r|r|r|}
\hline variable & \multicolumn{1}{c|}{ initial } & extract & variable & initial & extract & variable & initial & extract \\
\hline $\mathrm{X} 01$ & 0.988 & 0.993 & $\mathrm{X} 11$ & 0.998 & 0.985 & $\mathrm{X} 21$ & 0.981 & 0.967 \\
\hline $\mathrm{X} 02$ & 0.450 & 0.122 & $\mathrm{X} 12$ & 0.979 & 0.952 & $\mathrm{X} 22$ & 0.735 & 0.415 \\
\hline $\mathrm{X} 03$ & 0.882 & 0.628 & $\mathrm{X} 13$ & 0.979 & 0.908 & $\mathrm{X} 23$ & 0.968 & 0.871 \\
\hline $\mathrm{X} 04$ & 0.998 & 0.985 & $\mathrm{X} 14$ & 0.997 & 0.994 & $\mathrm{X} 24$ & 0.937 & 0.873 \\
\hline $\mathrm{X} 05$ & 0.979 & 0.933 & $\mathrm{X} 15$ & 0.998 & 0.986 & $\mathrm{X} 25$ & 0.990 & 0.903 \\
\hline $\mathrm{X} 06$ & 0.999 & 0.991 & $\mathrm{X} 16$ & 0.979 & 0.696 & $\mathrm{X} 26$ & 0.483 & 0.159 \\
\hline $\mathrm{X} 07$ & 0.877 & 0.604 & $\mathrm{X} 17$ & 0.951 & 0.920 & $\mathrm{X} 27$ & 0.516 & 0.347 \\
\hline $\mathrm{X} 08$ & 0.928 & 0.999 & $\mathrm{X} 18$ & 0.984 & 0.958 & $\mathrm{X} 28$ & 0.865 & 0.305 \\
\hline $\mathrm{X} 09$ & 0.996 & 0.952 & $\mathrm{X} 19$ & 0.991 & 0.942 & $\mathrm{X} 29$ & 0.993 & 0.907 \\
\hline $\mathrm{X} 10$ & 0.999 & 0.978 & $\mathrm{X} 20$ & 0.998 & 0.992 & & & \\
\hline
\end{tabular}

Based on the data of 71 cities from 29 selected indicators, the unweighted least-squares factor analysis method is used to reduce dimensions, and the original 29 variables are reduced to 4 unobservable synthetic variables to better promote urban development problem analysis. We use SPSS19.0 to implement the development factor measurement analysis of 71 cities including X01-X29 variables. Table 2 shows the common degree of variables. The table shows that most variables have a common degree over $90 \%$. The lower commonalities of variables are X2 and X26, which respectively represent the Population growth rate and Per capita green area. This shows that these two variables are not strong enough for urban development in these regions 
Indicators X2 and X26, X27 and X28 with lower common variables are not used. Using unweighted least squares factor analysis to analyze the remaining 25 indicators.Table 4 shows results. Table 3 shows results of the KMO and Bartlett test.The KMO statistic is 0.876>0.7, suitable for factor analysis. As for Bartlett's spherical test, Sig. 0.00 means that significant test counts.

Table 4 shows the eigenvalue, the variance contribution rate, the cumulative contribution rate, andthe first 4 factors' initial eigenvalue is greater than 1 . The cumulative variance contribution rate is $88.987 \%$, so choose the first 4 factors to measure the level of urban development.

Table 3. KMO and Bartlett's Test

\begin{tabular}{|l|c|c|}
\hline Sampling Sufficient Kaiser-Meyer-Olkin metric & 0.876 \\
\hline \multirow{3}{*}{ Bartlett's Sphere Test } & Approximate chi square & 4482.413 \\
\cline { 2 - 3 } & df & 300 \\
\cline { 2 - 3 } & Sig. & 0.000 \\
\hline
\end{tabular}

Table 4.Eigenvalue, variance contributionrate and cumulative contribution rate

\begin{tabular}{|l|l|l|l|l|l|l|l|l|l|}
\hline \multirow{2}{*}{ factor } & \multicolumn{3}{l}{ Initial eigenvalue } & \multicolumn{3}{l|}{ Extract square and load } & \multicolumn{2}{l|}{ Rotate squared and load } \\
\cline { 2 - 11 } & Total & Variance\% & $\begin{array}{l}\text { lacumulation } \\
\%\end{array}$ & Total & $\begin{array}{l}\text { Variance } \\
\%\end{array}$ & $\begin{array}{l}\text { accumulation } \\
\%\end{array}$ & Total & $\begin{array}{l}\text { Variance } \\
\%\end{array}$ & $\begin{array}{l}\text { accumulation } \\
\%\end{array}$ \\
\hline 1 & 17.574 & 70.294 & 70.294 & 17.507 & 70.028 & 70.028 & 13.015 & 52.061 & 52.061 \\
\hline 2 & 2.611 & 10.443 & 80.737 & 2.469 & 9.877 & 79.905 & 5.715 & 22.859 & 74.920 \\
\hline 3 & 1.540 & 6.159 & 86.896 & 1.277 & 5.110 & 85.014 & 2.252 & 9.009 & 83.929 \\
\hline 4 & 1.228 & 4.914 & 91.809 & .971 & 3.883 & 88.897 & 1.242 & 4.968 & 88.897 \\
\hline
\end{tabular}

Table 5.Regression method to get the normalized rotation factor score coefficient matrix

\begin{tabular}{|c|c|c|c|c|c|c|c|c|c|}
\hline variable & factor 1 & factor 2 & factor 3 & factor 4 & variable & factor 1 & factor 2 & factor 3 & factor 4 \\
\hline $\mathrm{X} 01$ & 0.046 & 0.182 & 0.625 & 3.473 & $\mathrm{X} 15$ & 0.395 & 0.122 & -3.864 & -3.892 \\
\hline $\mathrm{X} 03$ & 0.122 & -0.405 & 0.439 & 0.497 & $\mathrm{X} 16$ & 0.227 & -0.358 & -1.647 & -0.721 \\
\hline $\mathrm{X} 04$ & -0.226 & 1.132 & 0.688 & -3.635 & $\mathrm{X} 17$ & -0.254 & 0.401 & 0.217 & -0.093 \\
\hline $\mathrm{X} 05$ & -0.075 & 0.193 & 1.543 & -.185 & $\mathrm{X} 18$ & -0.648 & 0.725 & -0.591 & -1.808 \\
\hline $\mathrm{X} 06$ & 1.130 & 2.003 & 0.450 & -.953 & $\mathrm{X} 19$ & -0.482 & 0.551 & 1.341 & -0.677 \\
\hline $\mathrm{X} 07$ & 0.117 & -0.249 & 0.383 & .658 & $\mathrm{X} 20$ & -1.622 & 1.567 & -2.490 & -2.957 \\
\hline $\mathrm{X} 08$ & -0.026 & -0.378 & 0.661 & 1.973 & $\mathrm{X} 21$ & -0.103 & 1.093 & -1.131 & -0.624 \\
\hline $\mathrm{X} 09$ & -0.415 & 0.376 & -1.291 & -2.665 & $\mathrm{X} 22$ & -0.072 & 0.226 & -0.117 & -0.350 \\
\hline $\mathrm{X} 10$ & 1.591 & -1.672 & 2.310 & 5.053 & $\mathrm{X} 23$ & 0.073 & -0.360 & -0.396 & 0.017 \\
\hline $\mathrm{X} 11$ & 1.342 & -2.576 & 2.609 & 5.070 & $\mathrm{X} 24$ & -0.097 & -0.044 & 0.185 & -0.535 \\
\hline $\mathrm{X} 12$ & -0.535 & 0.361 & -0.416 & -.017 & $\mathrm{X} 25$ & -0.899 & 1.275 & 0.392 & -1.052 \\
\hline $\mathrm{X} 13$ & 0.233 & -0.754 & 0.225 & 1.368 & $\mathrm{X} 29$ & -0.946 & 0.237 & -1.894 & -0.899 \\
\hline $\mathrm{X} 14$ & 2.081 & -3.873 & 2.367 & 5.378 & & & & & \\
\hline
\end{tabular}

Table 5 shows the normalized twiddle factor score matrix obtained by using the regression method. The factor scoring functions FAC1_1, FAC2_1, FAC3_1, FAC4_1 are:

$$
\begin{aligned}
& \text { FAC1_1 }=0.046 \times 01+0.122 \times 03-0.226 \times 04+\ldots \ldots \ldots-0.899 \times 25-0.946 \times 29 \\
& \text { FAC2_1 }=0.182 \times 01-0.405 \times 03+1.132 \times 04+\ldots \ldots \ldots+1.257 X 25-0.946 \times 29 \\
& \text { FAC3_1 }=0.625 \times 01+0.439 \times 03+0.688 \times 04+\ldots \ldots \ldots-0.392 \times 25-1.052 \times 29 \\
& \text { FAC4_1 }=3.473 \times 01+0.497 \times 03-3.635 \times 04+\ldots \ldots \ldots-1.052 \times 25-0.899 \times 29
\end{aligned}
$$

Therefore, according to the square root of the variance of each factor of extraction, the total innovation score function S1 is:

$$
\text { S1=(13.015FAC1_1+1.754FAC2_1+0.839FAC3_1)/(13.015+5.715+2.252+1.242)(5) }
$$

According to formula (1) (5), the factor scores and total score of 71 cities in the Yangtze River economic belt could be calculated. In table 6, to the lowest rankings, Shanghai, Chongqing, Hangzhou, Suzhou, Chengdu and Wuhan ranks high.Cities ranklow areezhou, Zhoushan, neijiang, 
jingmen, and shiyan. The number before city is the number of city data record used for data analysis, for example, the number of data record of Shanghai is 1, other cities are similar.

Table 6.Development Score of 71 Cities in the Yangtze River Economic Zone

\begin{tabular}{|c|c|c|c|c|c|c|c|c|c|c|c|}
\hline City & ctor1 & Factor2 & Factor3 & Factor4 & Total & City & Factor1 & Factor2 & Factor3 & Factor4 & Total \\
\hline Shano & 75 & 79 & .96 & 0.94 & 4.19 & 5.Lishui & -0.13 & -1.05 & 0.03 & 1.75 & -0.25 \\
\hline .C & -1 & 4 & 59 & -1.03 & - & ou & .39 & 5 & -0.82 & 0.96 & -0.2 \\
\hline $5 . \mathrm{H}$ & 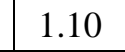 & + & 1.00 & 1.22 & 1.0, & 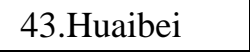 & 0.02 & -0.52 & -0.71 & -1.02 & -0.25 \\
\hline Suz & 1.69 & 0.10 & 2.38 & -2.00 & 1.07 & & -0.10 & -0.53 & -0.10 & -0.90 & -0.25 \\
\hline .Ches & -0.18 & 78 & 2.41 & 0.34 & 0.88 & 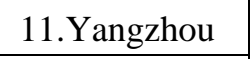 & -0.38 & -0.36 & 0.24 & 0.65 & -0.25 \\
\hline 5.W & 31 & 10 & 95 & 1.31 & 0.84 & 21.110 & -0.30 & -0.25 & -0.11 & -0.07 & -0.25 \\
\hline 6.Ningbo & 03 & 0.27 & 1.58 & -1.36 & 0.76 & 52.Bozhou & -0.37 & -0.29 & -0.59 & 1.66 & -0.26 \\
\hline Nanji & 84 & 0.08 & 1.45 & 1.14 & 0.72 & 59.Lu & -0.35 & 15 & -0.72 & -0.42 & -0.26 \\
\hline 3.Wuxi & 39 & 0.29 & 2.22 & -1.56 & 0.44 & 63.Suining & -0.18 & -0.07 & -0.94 & -0.89 & -0.27 \\
\hline 7.Nanto & 0.36 & -0.06 & 0.83 & 0.74 & 0.32 & 67.Meis & -0.07 & -0.43 & -0.68 & -0.91 & -0.27 \\
\hline 17.We & -0.07 & 0.89 & 0.17 & 1.05 & 0.26 & $68 . Y$ & -0.30 & 08 & -0.86 & -0.75 & -0.29 \\
\hline 24.Ta & 9 & -0.15 & 3 & 0.92 & 0.25 & 51. & 49 & 70 & -1 & 39 & -0.29 \\
\hline 38.H & 3 & $\Omega_{-1}$ & 1.38 & 0.36 & 0 & 6 & 34 & 3 & 3 & .53 & -0.29 \\
\hline 5. Ch & -0 & $\Omega_{-1}$ & 2.49 & 0.73 & 0 & & 25 & $-T_{2}$ & 1 & 50 & -0.29 \\
\hline $\mathrm{Y}$ & -( & & & & 0.07 & & 7 & & & 70 & -0.29 \\
\hline 21.Jinhua & & & & & & & 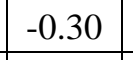 & & & & -0.29 \\
\hline $\mathrm{Li}$ & & & & & & & & & & 7 & 30 \\
\hline 4.Xuzhou & & & & & & & $-C_{-1}$ & & & 6 & 0 \\
\hline 18.Ji & 5 & & & & -0 & 4 & 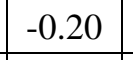 & U & 7 & 28 & -0.30 \\
\hline 39.Wuhu & -5 & -0 & 0.34 & - & -0 & 58.Panzhihua & -( & 1 & 4 & -2.55 & -0.30 \\
\hline 70.Dazhou & -0.11 & 8 & -( & & -0 & 45 & -0.30 & 0 & 72 & -0.55 & -0.30 \\
\hline 30.Xiangyang & -0.21 & -0.07 & & 0.84 & -0 & 36. & -0.16 & -0.78 & 0 & .71 & -0.31 \\
\hline 20.Shaoxing & -0.03 & -0.20 & 0.20 & -0.77 & -0.09 & 47. & -0.35 & 0.20 & 3 & -1.26 & -0.31 \\
\hline 12.Zhe & -0.18 & -0.40 & 0.94 & -0.04 & -0.11 & 37. & -0.46 & 3 & 3 & .41 & -0.32 \\
\hline 41. Hu & 0.20 & -0.60 & -0.44 & -0.72 & -0.12 & 4 & -0.39 & 8 & 9 & -0.42 & -0.34 \\
\hline 35. Hu & -0.21 & 33 & -1.20 & 0.49 & -0.13 & 5 & 0.34 & -0 & 15 & -0.27 & -0.34 \\
\hline 61.Mi & -0.49 & 0.26 & - & 0.86 & -0.14 & 49.Suzho & -0.46 & t- & 21 & .38 & -0.34 \\
\hline 69.Guang an & -0.26 & 047 & -1.22 & 0.44 & -0.15 & 54.Xuanche & -0.34 & -0.79 & 0.23 & 0.52 & -0.35 \\
\hline 33.Xiaogan & -0.04 & -0.42 & -0.64 & 0.83 & -0.15 & 71.Yaan & -0.10 & -0.76 & -0.41 & -1.13 & -0.36 \\
\hline Huaian & -0.48 & -0.02 & 0.26 & 1.72 & -0.17 & 53.Chizhou & -0.24 & & & 0.50 & -0.36 \\
\hline 8.Fuyang & -0.53 & & -1.16 & 2.44 & -0.17 & 28.Shiyan & -0.51 & -0.23 & -0.29 & 0.39 & -0.36 \\
\hline 4.Suqian & -0.23 & 0.02 & -0.48 & 0.06 & -0.18 & 32.Jingmen & -0.36 & -0.35 & -0.31 & -0.71 & -0.37 \\
\hline 13.Taizhou & -0.46 & 0.63 & -0.28 & -0.85 & -0.19 & 64.Neijiang & -0.18 & -0.28 & -1.13 & -1.37 & -0.37 \\
\hline 19.Huzhou & -0.31 & -0.28 & 0.64 & -0.28 & -0.21 & 23.Zhoushan & -0.47 & -0.89 & 0.47 & 1.19 & -0.39 \\
\hline 2.Quzhou & -0.13 & -0.67 & -0.05 & 0.67 & -0.22 & 31.Ezhou & -0.23 & -0.47 & -0.58 & -1.58 & -0.40 \\
\hline 0.Chaohu & -0.12 & -0.39 & -0.77 & 0.39 & -0.22 & & & & & & \\
\hline
\end{tabular}




\section{System Hierarchical Cluster Analysis}

The above runs an unweighted least-squares factor analysis on the growth of 71 cities in this economic belt and can be further analyzed by system-level cluster analysis using SPSS.

Figure 1 shows the dendrogram of 71 cities in the Yangtze River Economic Belt using system-level cluster analysis. Referring to scores of 71 cities in the Belt shown in Table 6, we find that urban developmenttoward stop, middle and back situation is consistent.71 cities can be grouped into three categories. The first category consists cities with top scores, Shanghai, Chongqing, Hangzhou, Suzhou and Chengdu.Cities in the top category own the largest horizontal axis values. Horizontal axis values of cities in the middle are large, while those in the last part are smaller. The left figure shows cities and city data record numbers, which are same as what in Table 6.From the left part of the development dendrogram of 71 cities in this economicbelt, we can analyze the classes that can be divided into the least difference or the smallest difference categories.

By analyzing the dendrogram of 71 cities in the Yangtze River Economic Belt clustered by system level, the results of urban clustering can be obtained as follows:

(1) In the middle group, Changzhou and Wuhan converge into a couple, Nanjing and Hangzhou converge together, Hefei, Nantong and Taizhou converge into a category, and gonging upwards to include Chengdu, and then converge into a category. Chengdu, Nanjing, Hangzhou and Hefei are both Capital cities. Changzhou, Nantong and Taizhou are famous cultural cities here. Shanghai and Chongqing first converge together as a couple as Shanghai and Chongqing are both municipalities and international metropolises. Wuxi, Suzhou and Ningbo converge into a category, which arefamous huge cities in Jiangsu and Zhejiang province in the Yangtze River Delta Economic Zone.

(2) In the following group, Ma'anshan and Panzhihua are converged, and the two metallurgical towns of Tongling and Ezhou are converged.Chuzhou, Deyang and Neijiang science and technology city group are aggregated into a cluster and then aggregated into a large category.Ya'anandMeishan polymerize as a category. Yichang, Leshan, Shaoxing and Wuhu polymerize as a category.These two categories converge up into a larger category. Bengbu, Zigong and Jingmen aggregates as a category. Suining, Yibin, Luzhou, Taizhou, Anqing polymerization as a class. These two classes go upwards into a larger class; then the two larger classes up into a category.

(3) In the above group, this group is composed of three stratified groups. In the uppermost group, Nanchong and Liu'an aggregates as a couple, and Huanggang, Guang'an, Suzhou and Dazhou are aggregated into a class and then polymerize upward into a big class. In the second group, Lishui, Huangshan, Jinhua, Zhoushan, Huai'an polymerization as a class, upward with Fuyang converged as a general category. In the next group, Zhenjiang, Huzhou and Jiaxing converge into acategory.Wenzhou and Xuzhou converge together into a couple.Lianyungang, Xiangyang and Mianyang are clustered into a class, and then the two groups are clustered into a larger category; Shiyan, Suizhou, Suqian, Huangshi and Yancheng clustered together as a category. Quzhou, Guangyuan, Chizhou, Yangzhou and Xuancheng polymerize as a category. Xiaogan, Xianning and Chaohu polymerize as a category, and Jingzhou and Bozhou converge into a couple, then polymerize into a larger category; then both these two groups class up into a large category. 


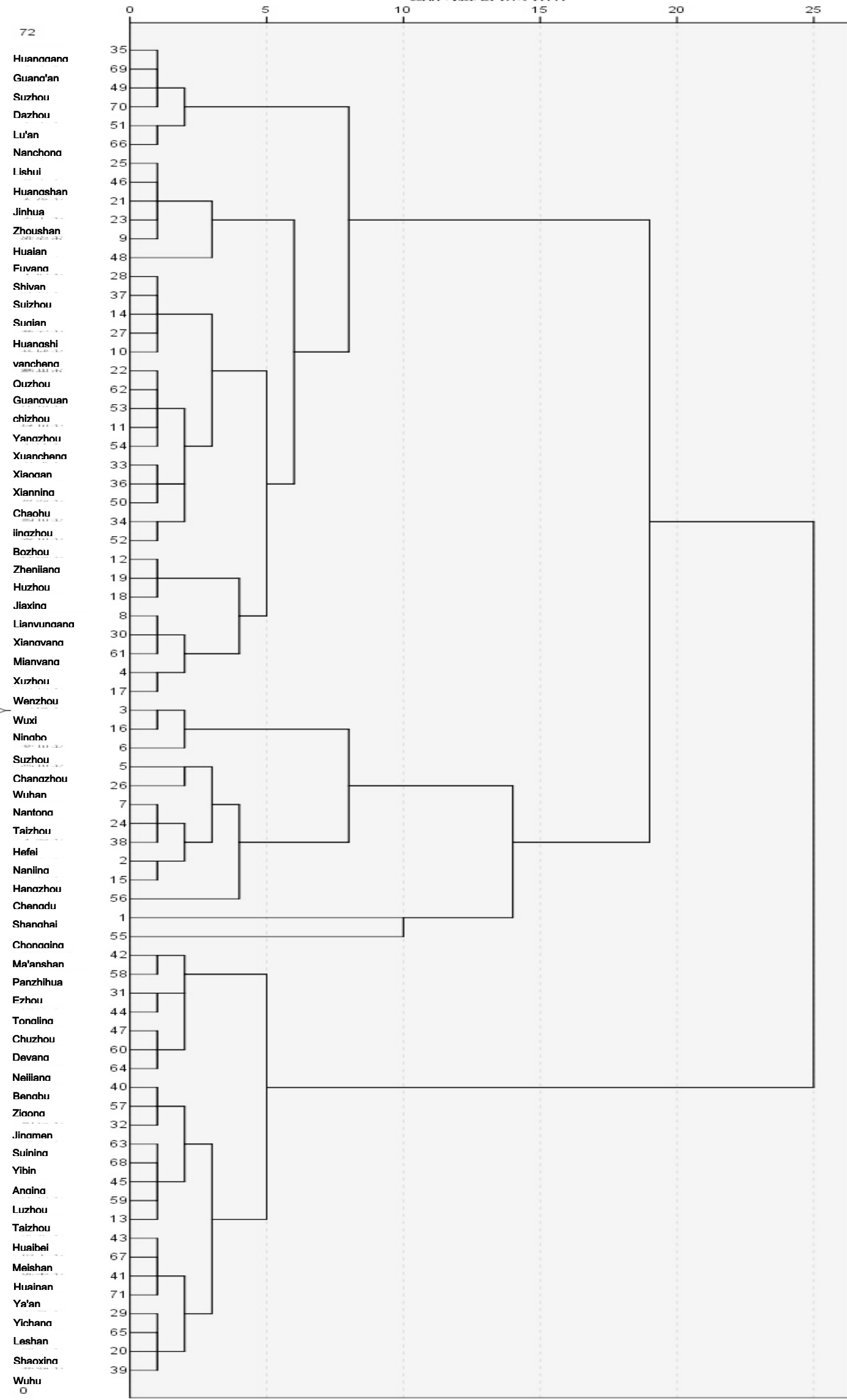

Fig 1. System-level clustering of the Yangtze River Economic Belt 71 cities dendrogram 


\section{Conclusion}

In summary, the conclusions are as follows:

(1) "Two horizontal and three vertical" is the strategic layout of urbanization in our country. It develops with land-bridge passageways and two horizontal axes along the Yangtze River.Three major longitudinal urban agglomerations as a Supporting Strategic Pattern of Urbanization. The Yangtze River Economic Belt is on an important axis of urbanization strategy with development at the forefront of the country. According to the score of the previous city rankings, it's better to combine characteristics of cities to promote the development of relevant regions.

(2) In general, the economic development of the cities in the Yangtze River Delta Economic Zone is the best. Shanghai, the city with the highest city ranking, is the leading urban core of the Yangtze River Delta. It is economic, commercial, financial, information, manufacturing and transport hub in China. Nanjing is the capital of Jiangsu province, the third city of science and education in China, and an important political, military, science and education, culture, science and technology, transportation, shipping and financial center in the country. Hangzhou is the capital of Zhejiang province, the core city of Hangzhou metropolitan area. It is an important economic, scientific, educational, cultural, financial, transportation and communications center in East China. The non-provincial capital cities with the highest city rankings are mainly the cities in the Yangtze River Delta Economic Zone such as Suzhou, Ningbo, Wuxi and so on.

(3) Chengdu-Chongqing Economic Zone has developed rapidly recently. Table 6 shows that Chongqing and Chengdu rank second and fifth respectively. Chongqing locates in the upper reaches of the Yangtze River. The Yangtze River and the Jialing River surround it. Chongqing has become a national central city, the largest integrated transport hub for water and land in the western region of the country, covering economy, politics, finance, innovation, shipping, culture, science,technology, education and communication. It is an important support for leading the accelerated development of the western region and enhancing the comprehensive strength of the countryin thedomestic space development strategy in China. Chengdu is the capital of Sichuan Province. It is the economic, financial, commercial, cultural and scientific center of southwest China.

(4) Wuhan Economic Circle is the fastest-growing economic zone in the central region. Located in the middle and lower reaches of the Yangtze River, Wuhan ranks sixth in urban development and is the provincial capital in Hubei Province. It is the financial, commercial, transportation, scientific research, education, trade and cultural center in the central part of China. Wanjiang Economic Belt in the Midwest to undertake industrial transfer has an important strategic position, located in the Yangtze River between the Yangtze River and the Huaihe River. It is an economic, financial and transportation center of Anhui, with North-South, east and west of the regional advantages.

(5) Cities in the Yangtze River Economic Belt are representatives of urban development in eastern, central and western China. Cities in the eastern Yangtze River Delta economic zone may speed up the growth of countries.Changing the mode of economic growth with increased labor costs, attaching importance to technological innovation and industrial restructuringand continuing to strengthen advantages of economic development are crucial. Chengdu-Chongqing Economic Zone, lying in the western part ofChina, the urban construction of Chengdu and Chongqing with "dual-core" function can step up, speeding up development, increasing the radiation capacity and boosting the economic growth in western regions. The Wuhan economic circle, lying in the middle, has a high degree of agglomeration in second industry. These industries need supports to sustain rising. Management in cities need strengthened. Emphasis can be placed on personnel training and investment in science and technology to promote economic development in central regions.

\section{Acknowledgement}

Fund Project: The Ministry of Education Planning Fund Project (17XJA630005); Sichuan Provincial Department of Education Key Project (17SA0135). 


\section{References}

[1]Xue Yan-jie, Wang Zhen. Analysis and Prospect on the Economic Situation of Yangtze River Delta Region:2011-2012[J]. East China Economic Management, 2012, 26(12): 30-34. (In Chinese)

[2]Tang Yun-yun, Cao Wei-dong, LuoJian, Jiang Xiao-wei, Zhu Sheng-qing. Study on the Evolution and Mechanism of Anhui's Economic Geography in the Past 20 Years[J]. Journal of Chizhou College. 2012, 26(12): 56-59. (In Chinese)

[3]Weng Mei-lan. Industrial Agglomeration and Urbanization Envelopment in Wuhan Economic Circle [J]. Business Forum. 2013(3): 209. (In Chinese)

[4]HeXiong-lang, ZhuXu-guang. Research on Industrial Structuring and Economic Development of Chengdu-Chongqing Economiczone[J]. Soft Science. 2010, 24(6): 74-79. (In Chinese)

[5]National Bureau of Statistics of China,ChinaStatistical Yearbook2017[M],China Statistics Press,2017. (In Chinese)

[6]Statistical Bureau of Jiangsu, Jiangsu Statistical Yearbook2017[M], China Statistics Press, 2017(In Chinese)

[7]Statistical Bureau of Sichuan,Sichuan Statistical Yearbook 2017[M], China Statistics Press, 2017. (In Chinese)

[8]Statistical Bureau of Hubei, Hubei Statistical Yearbook 2017[M], China Statistics Press, 2017. (In Chinese)

[9]Statistical Bureau of Zhejiang, Zhejiang Statistical Yearbook2017[M], China Statistics Press, 2017(In Chinese)

[10] Statistical Bureau of ChongQing, NBS Survey Office in ChongQing: ChongQing Statistical Yearbook 2017[M]], China Statistics Press, 2017. (In Chinese) 